\title{
A SYNTHESIS OF SLOAN-C EFFECTIVE PRACTICES
}

December 2009

Updated with links May 2010

Janet C. Moore

Chief Learning Officer

The Sloan Consortium

\begin{abstract}
Encouraging continuous improvement in the quality, scale and breadth of online education, the Sloan Consortium invites practitioners to share effective practices. This report synthesizes effective practices submitted by Sloan-C members to the online collection at http://www.sloanconsortium.org/effective as of December 2009. The synthesis includes links to the provider institutions and to detailed postings about practices.
\end{abstract}

\section{KEYWORDS}

Learning Effectiveness, Scale, Institutional Commitment, Access, Faculty Satisfaction, Student Satisfaction, Quality Framework

\section{CONTENTS}

I. INTRODUCTION 74

II. STUDENT SATISFACTION__ 75

1. How can schools help learners get started with online learning? _

2. How can schools help learners make good choices? __ 76

3. How can schools build community among learners? _ 76

4. How can schools and faculty assess student satisfaction?

5. How can schools increase student satisfaction with learning? $\_78$

6. How can schools use technology to enhance student satisfaction?

III. LEARNING EFFECTIVENESS _ 79

7. How can learning design enhance interaction?

8. How can learning design enhance collaboration?___ 80

9. How can learning design inculcate academic honesty? ___ 81

10. How can schools assess learning effectiveness? ___ 81

11. How can technology support learning?

IV. SCALE

12. How can schools share resources to improve learning and avoid costs? __ 82 
13. How can redesign improve access, affordability, and learning, and save effort? 83

14. How can schools use technology to improve strategic planning?

15. How can schools use technology to provide cost effective services

for faculty, students and administrators?

V. ACCESS

16. How can specialized online student services and resources make access easier? 85

17. How can schools help students access support and adapt to academic culture? 86

18. How can schools provide access to special populations? 86

19. How can schools use technology to improve access? 88

VI. FACULTY SATISFACTION 89

20. How can schools foster greater community among faculty? 89

21. How can schools prepare faculty to teach online more effectively? 90

22. How can schools encourage and support research opportunities for faculty? 91

23. How can schools recognize and reward faculty who teach online? 91

24. How can technology help organize and enhance faculty activities? 91

\section{INTRODUCTION}

The Sloan-C Effective Practices collection enables educators to share practices that help make quality online education more affordable, accessible and effective. Sloan-C's quality framework calls for metrics to measure progress towards these goals via the five key principles that are known as pillars for achieving quality. Effective Practice postings demonstrate evidence of effectiveness in each of these pillars.

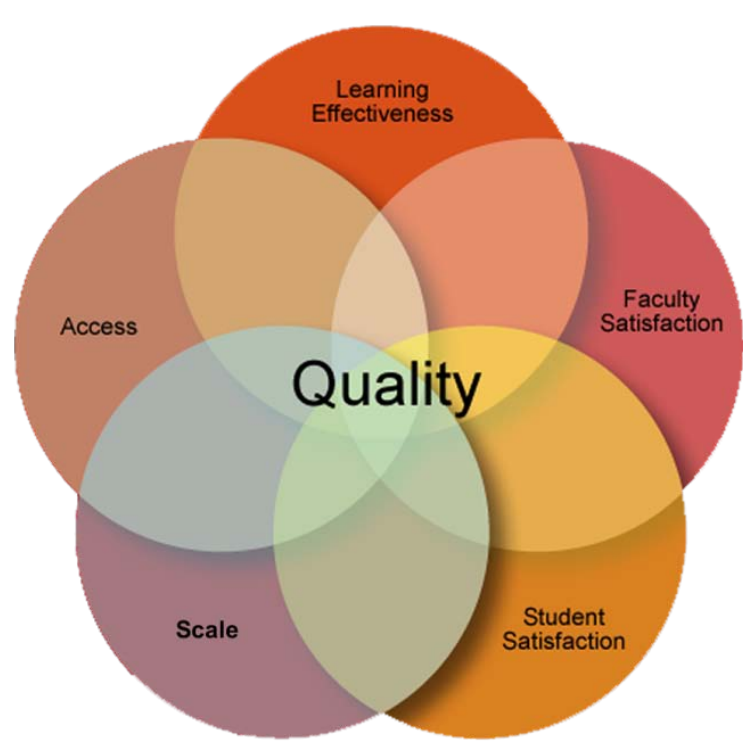

Learning Effectiveness: Online learning outcomes meet or exceed institutional, industry, and/or community standards.

Scale: Institutions continuously improve services while reducing cost to achieve capacity enrollment.

Access: All learners who wish to learn online have the opportunity and can achieve success.

Faculty Satisfaction: Faculty achieve success with teaching online, citing appreciation and happiness.

Student Satisfaction: Students are successful in learning online and are pleased with their experience.

As technology introduces new possibilities, the effective practices collection is a collaborative work in progress. Educators share emerging knowledge and advance it, and Sloan-C recognizes excellence, awarding practices that meet these criteria:

- Innovation: The practice is inventive or original.

- Replicability: The practice can be implemented in a variety of learning environments.

- Potential impact: The practice would advance the field if many adopted it. 
- Supporting documentation: The practice is supported with evidence of effectiveness.

- Scope: The practice explains its relationship with other quality elements.

Practices in one area affect quality in others, thus the pillars are related and interdependent. When members post practices, they help influence the future of education. Practices are automatically eligible for annual Sloan-C awards. Appendix A lists effective practice awards, and Appendix B is the rubric for evaluating effective practices.

This synthesis groups effective practices according to solutions that contributors have provided to some frequently encountered questions. Hyperlinks are provided so that readers can examine details about practices and the organizations and people who have generously shared them.

\section{STUDENT SATISFACTION}

Sloan-C's goal for student satisfaction is that students are successful in learning online and are typically pleased with their experiences. Measurement of student attitudes finds that:

- Discussion and interaction with instructors and peers is satisfactory;

- Actual learning experiences match expectations;

- Satisfaction with services (advising, registration, access to materials) is at least as good as on the traditional campus;

- Orientation for how to learn online is satisfactory; and

- Outcomes are useful for career, professional and academic development [1].

Student satisfaction with the entire learning experience begins with preparing learners for the online environment, continues throughout the curriculum, and continues past graduation with career services and lifelong learning. As emphasized by the Western Cooperative for Educational Telecommunications 2002 report "Beyond the Administrative Core: Creating Web-Based Student Services for Online Learners," "students expect more than static web pages - they are looking for personalized and integrated information and services that will support their higher education experience [2].”

\section{How can schools help learners get started with online learning?}

A full range of online services comparable to services provided on campus helps ensure that the quality of learning is at least equivalent to learning in face-to-face settings. The Illinois Virtual College Online Student Resource Center (IVC) helps students succeed in online learning with online resources for: Getting Started, Student Resources (Assessment \& Testing; Diverse Populations; Financial Assistance; Health \& Wellness; New Students; Purchasing Books Online; Returning Adult Students; Transfer Information), Academic Success Skills (Study Skills/Online Tutoring Sites; Library Skills/Online Research Sites; Writing/Communication Skills; Survival Skills; GPA Calculator), Career \& Life Planning (including tutorials that walk students through planning process), and Technology Tools (including tutorials). Students interested in taking an online course can walk through the resources at their own pace, or they can go directly to a category of information. Students at all 66 Illinois campuses can also visit in person any of 40 IVC Student Support Centers, one located in every community college district in the state. Stark State College requires students to complete an agreement that tells them what to expect and how to succeed. Fernuniversitat Hagen provides online tools for enhancing learning effectiveness for easy access to personal data and calendars, assignment results, courses, and contact information for tutors and classmates. At the University of North Texas ecampus, a student guide meets all five pillars of quality by providing access to course information for online students, student satisfaction in knowing that they are 
prepared for the academic and technical requirements of the online course, learning effectiveness in permitting students to get a head start on course requirements, faculty satisfaction in knowing that their students know about course expectations, and cost effectiveness and institutional commitment in making course and program information available to prospective and current students before they decide to enter. University of North Texas also requires beginning students to enroll in Web Institutes so that student cohorts support one another. At Saint Leo University, a required online orientation introduces learners to resources and expectations, with an overview of support services and resources, through an online, instructor-led orientation course that assures connection and connectivity to entry level students. At GoArmyEd (formerly eArmyU), ViCTORY (Operation Virtual Counselor Transforms Online Resources for You) is a model for Soldier academic support and success; this fully integrated proactive studentsupport reaches out to soldiers in more than 50 countries. GoArmyEd counselors regularly contact soldiers at critical points in their progress, helping to ensure a high rate of completion. Similarly, mentors at Western Governors University know that learners' approaches in its competency-based program may range through a continuum of transforming, performing, conforming or resisting, and so mentors establish regular contact with learners to reduce feelings of frustration and isolation. Long Beach City College (LBCC) provides its orientation on learning skills, Internet skills, and communication skills to all LBCC faculty and students and to others who wish to use the resources at S.I.D.E. Road: Success in Distance Education. Washington State University helps students learn to communicate online with the help of virtual facilitators.

\section{How can schools help learners make good choices?}

To help students project and manage their time and also to help decide which courses they can succeed in, Troy State Montgomery provides a syllabus display and time on task as part of the registration process. At Athabasca University, the detailed syllabus helps students preview expectations before taking the course and reduce anxiety, pace themselves and even work ahead of schedule to accommodate business and personal commitments. At the University of Phoenix (UOP), personalized, student-centered life-long learning for adult learners includes consideration for the schedules of working adults; thus, courses are taken one at a time during a six-week-long intensive semester. UOP's small class size, academically qualified practitioner faculty, and outcomes oriented curricula focus on providing students with workplace competence, teamwork practice, and improved communication skills. At Washington State University, flexible enrollment options offer students control of learning, so that they can choose to enroll in a regular semester or extend for a couple of semesters. To help establish social presence and preview subject matter for prospective students, Washington State University provides brief RealPlayer videos in which the professor welcomes students with an introduction to the course. Empire State College requires a course that becomes an educational planning environment in which students and their mentors assess their preparation for college; consider personal, professional and educational goals; identify prior learning; analyze what students need to learn; select courses; choose a concentration, make a curricular plan, and develop and articulate a degree program. At Northern Virginia Community College, a tutorial instructional model builds learner-instructor interaction into course, assignment, submission and feedback processes.

\section{How can schools build community among learners?}

Because student satisfaction is rooted in a learning community, The Pennsylvania State University World Campus's community website connects online students to the university and builds a learning community; and its student/faculty helpdesk, an online customer service, makes online experiences more satisfying for faculty and online students. At the State University of New York Learning Network (SLN), courses emphasize the importance of required interactions between student and faculty, and SLN continuously assesses student satisfaction and reported learning, interaction, learning community formation, and more. 
To encourage its graduates to stay identified with its community, University of California Berkeley offers tuition discounts for alums for online courses.

To prepare its students for their online course experience, Berkeley College has a comprehensive plan for preparing online students including an orientation site for its online degree students, a required online preparatory course that prepares online students to understand the particulars of online learning and navigate the course management system, an online library orientation, a special one-stop shopping center online degree site with messages from advisors and students services, an online tutoring site that is always available to help students with course material and writing assistance, and ongoing faculty and technical support. At Rochester Institute of Technology each online course has a customized course page with course information, school policies, access and equipment information, and resources. Frederick Community College (FCC) provides a comprehensive array of online library materials and services. Library resources available by remote access include the library catalog, reference data bases, online journals and full-text resources, government documents, news services, and other sources. The library also creates custom web pages with resources that are relevant to individual courses. Services provided online include reference and research assistance, document delivery, interlibrary loan, partnering programs with local libraries, and library user training, including research techniques.

To welcome students to the course community, a professor at Charter Oak State College telephones students on the first day of class to establish communication. At Mercy College, students feel more comfortable about asking for assistance when they can ask their peers, students who are tutors, facilitators, and role models. At the University of Massachusetts Lowell, a course community and resource website builds community building through sharing of student pictures, current and past student work and extensive resources. The University of Arizona College of Nursing Online PhD Program rotates student photos on its portal as an easy way for learners to match names with faces. "Well begun is half done" at Old Dominion University where the online student orientation website an interactive gateway that helps prospective students to become acquainted with distance learning. Students can assess their computer proficiency, learn about course registration and choose from a variety of helpful tutorials. Faculty may refer students and advisees to the site and it can easily be embedded into a preexisting website or course site. The Orientation site not only serves as an efficient segue to distance learning, but also proves to be an encompassing resource that can be referenced throughout distance learners' academic careers. Connecticut Distance Learning Consortium provides a collaboratively designed eportfolio platform to support learning, reflections, advising, career services, and assessment. Students use the platform to track and annotate their education, experience and goals. They can collect samples of their work to create portfolios and showcase specific experiences, photos, career documents, and portfolios to invited faculty, peers, employers, or others. A "counselor” view allows students to work virtually with advisors and career counselors.

At Saint Joseph's College of Maine, proactive academic advising for distance students meet the institutional goal of providing distance students with access to the same or better resources as their campus-based counterparts. Academic advisors maintain regular contact with prospective students via phone, mail, and email, and help students evaluate their academic and technical readiness for distance learning. Along the way, they encourage students to consider how their pursuit of distance education will fit into their family and work lives and to solicit support from family and friends. Students help students learn at Mercy College where students who have excelled in online courses become "wizards," online teaching assistants. In Mercy College 's Master of Organizational Behavior program cohorts build online learning community as learners engage with permanent 12-month cohort of learners, with a permanently assigned mentor, and a permanent team of instructors; learners report a transformation in their academic, personal and professional development; and the program boasts a $90 \%$ success rate. 


\section{How can schools and faculty assess student satisfaction?}

To make sure it provides a satisfying learning experience for graduate students, the Stevens Institute of Technology's WebCampus monitors student satisfaction and other responses every semester by surveying its online graduate students to find out how eager students are to learn and to be involved with their learning environment, how ready they are to collaborate with other students, and how at ease they are with their instructors. Students perceive that their learning is on a par with traditional modes and that the programs provide what they desire in graduate education.

Professor Denise Marchionda at the University of Massachusetts Lowell realized students would appreciate guidelines for managing the online week, so she provided a template for structured activities; students appreciate the guidelines and the distributed pacing of activities, and the template eliminates questions and reminders about the schedule.

\section{How can schools increase student satisfaction with learning?}

Learning designed for student satisfaction is convenient, flexible, relevant, personalized, and engaging; it offers learners options for learning activities and for controlling the pace of learning.

The University of Massachusetts uses the real-time case method to enhance the learning experience, providing extended, in-depth coverage to students at many schools, with real-time interactivity with the case company. Students report high satisfaction with the authenticity of the real case study work that sustains their interest and enthusiasm. Also at UML, a pause and post method improves the frequency and quality of discussion board posts in an education course.

Capella University students visit its online writing support center frequently and appreciate the writing tips featured regularly on its learning portal.

The Pennsylvania State University finds that learners enjoy ePortfolios as a way to evaluate their learning experiences and to share their reflections with peers and potential employers.

For designing and conducting large classes that are intellectually engaging and satisfying for students, Professor Murray Turoff of the New Jersey Institute of Technology provides tips for managing large groups effectively: synchronizing, organizing, socializing, collaborating, sharing and feedback.

At the University of Toledo, an online writing center increases satisfaction among students and faculty by helping students improve writing skills and avoid plagiarism.

\section{How can schools use technology to enhance student satisfaction?}

To create a website that intuits and satisfies expectations, Embry Riddle Aeronautical University surveyed its constituents and also invited visitors to give feedback on its website design and incorporated results to create a thoughtful web design that welcome current and perspective users. Another platform designed with users in mind, Moodle is an open-source learning management system designed by faculty with continuous feedback from users as a user-friendly interface for constructive interaction with content and classmates. Designed with a social constructivist framework, Moodle includes many features to enhance social, cognitive and teaching presence: user friendly overall design; easy course, user, and site management; assignment, chat, survey, forum, quiz, and resource modules; and wiki (collaborative 
writing), encyclopedia, and glossary functions. University of Nebraska in Lincoln (UNL) uses video conferencing so that doctoral students can present their work without having to travel. Faculty at three universities-West Virginia University, University of North Carolina at Charlotte, and Virginia Techfound that audio feedback enhances student satisfaction and saves faculty time. At American Public University (APUS), students use online collaborative document editors which streamline project workflows and improve cognitive outcomes because of easy collaboration, easy multimedia inclusion and manipulation, and the relationship between online document collaboration tools and wikis.

\section{LEARNING EFFECTIVENESS}

Sloan-C's goal for learning effectiveness is evidence that the quality of learning online is comparable to the quality of traditional programs, meeting or exceeding industry standards for learning outcomes. Metrics for learning effectiveness may demonstrate that:

- Interaction is key: with content, with instructors, classmates, the interface, and via vicarious interaction

- Online and traditional courses achieve comparable learning outcomes

- Online course design takes advantage of capabilities of the medium to improve learning (testing, discussion, materials)

- Communications and community building are emphasized

- Swift trust characterizes the online learning community

- Distinctive characteristics of programs are highlighted to demonstrate improved learning

Learning effectiveness online benefits from community efforts that help learners adjust their roles to become more aware of learning, more motivated and self-directed, and more confident in online environments. As Swan explains, learning effectiveness benefits from purposeful interaction; see Relationships between Interactions and Learning In Online Environments [3], a concise summary of the principles of interaction, many of which are exemplified in the effective practices listed in this synthesis. A continuing large-scale collaboration among educators who understand the significance of interaction in learning is The Community of Inquiry Framework -it is demonstrably effective for Multi-Level Institutional Evaluation and Continuous Quality Improvement.

\section{How can learning design enhance interaction?}

Perceptions of learning effectiveness correlate with perceptions of social presence. At Florida State University, social presence begins with introductions in which students complete a personal profile complete with photo; profiles are accessible to the members of the course. Courses at the State University of New York University at Albany are designed for effective discussion management via modules for readings with critiques, lesson planning, and reflective journals that lead to abundant professor-student interaction.

For effective interaction, students and faculty benefit from clear expectations about communicating; clear expectations help manage the volume and quality of interaction. Thus, Prince George's Community College finds that improving navigation helps students find what they need and cuts down on questions to faculty. Clark College advocates front-loading content in course design so that students have already engaged with course work before they attend their first class meeting. 
Across its curriculum, Mercy College finds that defining effective participation helps learners contribute postings that are: substantial (relate to the course material), concise (one screen may be the ideal message length), provocative (encourage others to respond), hermeneutical (expand concepts or connects ideas in new ways), timely (occur in a reasonable time frame-when the topic is under discussion), logical (support point of view with reasons and evidence), and grammatical (are well written). At Herkimer Community College, Professor Bill Pelz encourages student-led discussion to build complex understandings of psychology concepts; discussions require postings that are relevant, important, thoughtprovoking, original and timely. Moreover applying research on presence to guide online discussions, Pelz helps students develop social, cognitive and teaching presence by grading for postings that document, explain and apply information that contributes to the understanding of some issue under discussion so that classmates gain insight into the subject, and learners become teachers.

Miami University finds that using the Quality Matters rubric to guide online course development, including emphasis on interaction, builds quality assurance into the final product; likewise Seton Hall University relies on the Quality Matters rubric to provide faculty with a consistent foundation for developing online courses. Emphasizing interaction (with content, peers, teachers, and interface [2]) aids collaboration, one of the most important aspects of online education; thus, a professor of education at Kent State University designs courses that include opportunities for both individual and group work via personalized instruction and problem based learning.

Second Life is a highly interactive virtual world that is proving engaging for faculty and students alike. Sloan-C hands out note-card directions in Second Life and identifies avatars by students' real names.

\section{How can learning design enhance collaboration?}

Asynchronous learning networks (ALN) optimize opportunities for collaborative learning and demonstration of learning. The University of Florida's Internet MBA uses online peer evaluation of writing assignments so that students give reciprocal feedback on each others' projects. For teachers in training, the University of Cincinnati's early childhood learning community uses multimedia for virtual assessment of and reflection on student teaching to enable students to do student-teaching in their own communities, and use online channels to self-evaluate, to obtain mentoring, and to create online journals and portfolios. At the University of Massachusetts Lowell (UML), professors in various disciplines use online resources to enhance learning. A UML education course uses electronic portfolios for organizing and assessing; each student builds an individual repository of materials, demonstrating industry and growth across a semester's worth of work. Portfolios help students and faculty demonstrate and track learning. At UML psychology professor provides a publication in personality psychology that integrates original writings of theorists, case studies and personality assessment inventories, so that students can apply, personalize and critique theoretical knowledge. UML accounting professors enable the practical application of accounting concepts using EDGAR, the Security and Exchange Commission's (SEC) electronic data gathering, analysis, and retrieval system so that students have meaningful illustrations and practical applications of financial reporting using actual SEC data. At Stevens Insitute of Technology professors use virtual teams for teaching marketing in an online course so that students learn experientially, doing actual marketing projects in collaboration.

A special collection of effective practices focuses on student-generated content as a special affordance of online learning that encourages active learning and demonstrable outcomes. At North Carolina State University, students enjoy electronic peer review for giving each other feedback, improving skills, and building on each other's work. At the University of Reading's School of System Engineering, students produce assessment learning objects to help each other learn programming. Minneapolis College of Art 
and Design showcases an online gallery of student and alumni work so peers and prospects can share inspiration. At Northern Virginia Community College students publish their own practical applications of math problems. Podcasting performances helps students develop skills in speaking English. At the University of North Carolina at Pembroke, students have created an Online Encyclopedia of Criminal Justice and gain experience "editing, revising, and organizing the content."

\section{How can learning design inculcate academic honesty?}

Adjustment to online learning includes understanding institutional policies for academic honesty and integrity. Florida State University applies the same honor code online and face to face. The Virtual Academic Integrity Laboratory (VAIL), visitors to the online University of Maryland University College Center for Intellectual property find resources for faculty and administrators and for students. To verify identity, Pace University provides secure testing for online learners through a proctoring network.

\section{How can schools assess learning effectiveness?}

In the University at Albany's computer and media education courses, students participate in and learn to create lesson plans incorporating rubrics - not only do rubrics help assess student performance, by helping students focus on what matters in the course, they help refine the course and reduce questions about grades, easing faculty workload. Massachusetts Institute of Technology recognizes that a common objective scale for quality can benefit higher education efforts in joint development and shared resources, ultimately reducing the overall costs of online learning. Thus, MIT proposes a new methodology for evaluation: the pedagogical rating of online courses. This tool for overall evaluation of online courses or modules demonstrates that pedagogical effectiveness increases as cognitive opportunity increases, via attention to learning styles, media elements, and interaction. Michigan State University uses LON-CAPA, open source freeware for assessment and content management, to obtain immediate, detailed feedback about online homework, which can be used to quickly adjust lectures, recitation sessions, and individual help to address learner needs. The University of Wisconsin-Madison's Master of Engineering in Professional Practice has an integrated assessment system for courses, overall program and post-program career impacts that includes an evaluation of each course by students and faculty; an evaluation of the overall program at graduation; and a follow-up survey of alumni, their co-workers, and their family members to measure the impact of the program upon professional and personal development of alumni. The practice provides evidence of continuous improvement through regular team review and implementation of assessment results. At the College of Southern Maryland, professors incorporate assessment in three ways: 1) creation of a learning guide (explicit roadmap), 2) reorganized presentation and design, and 3) addition of classroom assessment techniques (CATs) in each course module. Students "welcomed the opportunity to participate in activities to assess their learning more frequently throughout the course."

\section{How can technology support learning?}

Learning benefits when relevant, active, interaction with content enables learners to apply skills and concepts. Technology offers options for simulations, online labs, and collaborations that support active learning. At Rio Salado, an online class helps students actively learn human anatomy using online resources such as interactive tutorials, tests, puzzles, practice labs, games, and written assignments. A course at Riverside Community College shows that outcomes improve when students have online access to elementary algebra with interactions, tutorials and workshops. Sheffield College boasts $100 \%$ success rates in its preparatory English certificate that helps students qualify for university entry. At William Rainey Harper College, a chemistry course includes a lab environment that demonstrates applications of theoretical concepts, including lab applications via blended learning, combining online and face-to-face 
learning. A course in ethics at the University of Massachusetts Lowell uses a mock trial to engage students in critical thinking about technology. Stanford designs custom tutorials using courselets, selfcontained, integrated sets of learning materials for unlimited practice and review to enhance the learning experience for students and reduce the demand for faculty time. At Indiana University, the TALON Learning Object System provides repurposeable learning objects that faculty can easily adapt to create interactive content for writing, visual learning, math and more so that students can master skills and content. The University of Vermont College of Medicine transformed traditional education with an integrated curriculum that includes a wide variety of multimedia educational technology tools and applications for hybrid learning environments, including reusable learning objects, virtual reality models, streaming audio and video, and online exams. Because students interact with the self-directed, online educational tools at their own speed on their own time, prior to attending face-to-face lectures, faculty have been more efficiently focusing their face-to-face time with students in class. At Carnegie Mellon, speakers of English as a second language use an automated reading tutor that listens (Project LISTEN) and "intervenes when the reader makes mistakes, gets stuck, clicks for help, or is likely to encounter difficulty.” Kansai University receives positive evaluations from students who receive lectures at home via $3 \mathrm{D}$ virtual space.

WGBH PBS models rich multimedia content that is both educational and entertaining in its Nova program The Elegant Universe - each segment provides online transcripts, assignments, animations, interactivities, links to related sites and references, technical support, cinematography, narrative, video clips, and audio including music.

\section{SCALE}

Scale enables institutions to offer their best educational value to learners and to achieve capacity enrollment. Scale in online education is often a reflection of institutional commitment to providing quality online, so that online education achieves outcomes that are at least equivalent to outcomes achieved in other delivery modes in ways that are affordable for providers and for learners. In many cases, as the practices listed here demonstrate, online programs create efficiencies for "avoiding, reducing, and conserving costs" [4] that exceed those in traditional modes. An overview of issues institutions face in scaling online programs is provided by Oakley and Moloney [5].

- Institutions continuously improve services while reducing cost to achieve capacity enrollment

- Cost effectiveness models are tuned to institutional goals

- Tuition and fees reflect cost of services delivery

- Scalability, if an institutional objective, can be accommodated

- Partnering and resource sharing are institutional strategies for reducing costs

- Mission-based strategies for cost reduction are continuously formulated and tested

- Intellectual property policies encourage cost effective strategies

\section{How can schools share resources to improve learning and avoid costs?}

Consortia and other partnerships offer institutions opportunities to improve quality by sharing knowledge, resources and costs. In the Virtual Library of Virginia (VIVA), 39 state-supported colleges and universities in the Commonwealth of Virginia use technology to improve learning and productivity, and at the same time avoid costs (estimated $\$ 74.5 \mathrm{M}$ ) by sharing library resources online. WISE Web-based Information Science Education) is a collaborative for sharing library and information science resources. The Colorado Community Colleges Online share the costs of online services including student admissions, records, advising, and bookstore. Business schools at four different universities from Canada 
A Synthesis of Sloan-C Effective Practices, December 2009

to Florida collaborate in using the real-time case method (RCTM) to enhance learning and reduce costs RCTM is scalable to more universities.

\section{How can redesign improve access, affordability, and learning, and save effort?}

Re-designing courses can improve learning and access, free up faculty time, reduce physical plant costs, reduce dropout, failure, withdrawal (DFW) rates, and maintain or increase enrollment. The National Center for Academic Transformation demonstrates how substitutions of technology for labor increase access, achieve cost savings, and utilize technology to facilitate learning. In courses in multiple settings, universities are able to reduce classroom space and contain costs or achieve some cost savings by substituting a primarily asynchronous learning model for the traditional classroom model.

A redesigned computer literacy course at the University of Buffalo produced 54-60\% reductions in cost per student. An introductory psychology course at University of Southern Maine reduced lecture time, increased interaction and completion rates, and reduced cost per student by more than $50 \%$. At the University of Dayton, redesign reduced course sections of introductory psychology by $50 \%$ by combining sections with more collaborative and interactive learning models. At Brigham Young University, redesigning Freshman Composition resulted in less time in class, greater interaction, and maintained learning outcomes and satisfaction; Vanderbilt University's distributed learning electronics labs increase access and decrease the number of trips to a physical lab at a reduced cost. At Virginia Tech, an online math course eliminates class meetings, maintains learning outcomes, and improves completions. At the University of Iowa, a redesigned chemistry course enables students to report homework and laboratory results online, with a cost savings of about $\$ 10$ per student. Indiana University-Purdue University Indianapolis lowered the cost of introductory sociology by about $20 \%$ while improving learning outcomes and completion rates. An introductory Spanish course at the University of Tennessee Knoxville reduced faculty workload by automating grading; the redesigned course increased enrollment and achievement. The Pennsylvania State University redesigned an introductory statistics course with a $30 \%$ reduction in cost per student, reducing lecture and preparation time, adding computerized testing, and increasing interaction. Faculty at West Chester University improved instruction and reduced workload by introducing a virtual biology laboratory. Western Kentucky University's self-paced, web-based computer literacy course reduced cost per student by two-thirds while increasing enrollment more than threefold. The University of Central Florida redesigned a course in American National Government, and anticipates annual cost avoidance of $\$ 70 \mathrm{~K}$ in physical space while increasing collaboration and interaction. With the addition of a teaching assistant, Rio Salado redesigned math courses to reduce faculty staffing and increase enrollments with a decrease in per student costs of 37\%. The University of Maryland University College introduced interactive faculty training via CD-ROM to provide a standardized, high-quality, flexible, and reusable delivery mechanism to worldwide faculty in its more than 3000 sections of faculty training; its online faculty development workshops emphasize direct application so faculty can immediately implement what they learn.

\section{How can schools use technology to improve strategic planning?}

At The Pennsylvania State University, cost effectiveness means balancing educational outcomes and costs, thus The Pennsylvania State World Campus adopted a budgeting system that includes the costs of faculty compensation, instructional design, faculty development activities, marketing, and student services administration. The University of California, Davis compares face to face and online courses for cost-effectiveness and student pass rates, linking student learning outcomes with development and delivery costs. Central Virginia Community College has a comprehensive plan to enhance the quality of online education via assessment and five-year goals. Michigan State University's Office of MSU Global created an effective 5-phase business planning and costing model that streamlines the development and 
implementation process for online degree and certificate programs; its program costing model aims to ensure return on investment; and its global academic business planning model helps plan and implement hybrid degree and certificate programs in partnership with international higher education institutions. Florida State University's Office for Distributed and Distance Learning created an About Online Learning @ FSU website that features snapshots of online learning data under six categories that reveal a variety of information about FSU's courses, students and instructors related to FSU's online degree programs. This website has become a tool for reflective and demonstrative purposes that can ultimately lead to teaching and learning improvements and for strategic planning. At the University of North Texas, the Quality Enhancement Program is an ongoing process for accreditation that "meets all five pillars of quality by providing access to information about the QEP through presentations to thousands of faculty and students, student satisfaction in knowing that the university is focusing much effort into improving the undergraduate experience, learning effectiveness in engaging students in active problems-based learning, faculty satisfaction in being empowered to unleash their creativity and do what they do best - share their passion for their subject matter, and cost effectiveness and institutional commitment in providing an institution-wide focus on making big classes better.”

\section{How can schools use technology to provide cost effective services for faculty, students and administrators?}

Kentucky Virtual University planned for effectiveness and efficiency by creating a one-stop shopping portal that collocates admissions, registration, resources, the virtual library (KVL), the virtual high school (KVHS), and adult education (KVAE). Duquesne University provides important financial information to students by listing the various funding options on its tuition web page. The Pennsylvania State University's comprehensive academic advising and information system saves approximately $\$ 1 \mathrm{M}$ and considerable transaction time while giving students more responsibility for learning. Florida State University created an efficient and user-friendly test proctoring process that reduces duplications and eliminates the need to mail exam materials to proctors. At Pace University, secure testing and asynchronous faculty and curriculum development tools provide support to faculty, and curriculum development projects improve student and faculty satisfaction with little or no additional cost. An online faculty staffing tool is a more efficient means of scheduling faculty course assignments at the University of Maryland University College. The Rochester Institute of Technology's History Department cost effectively built an online course with free materials and, in the process, created an online inventory of resources that are freely available online for other educators to create web-enhanced, blended or fully online humanities and social science courses.

\section{ACCESS}

Access for anyone who is qualified and motivated to pursue studies calls for administrative and support services and for more choices for more learners and more kinds of learners. Thus effective practices in access show how organizations facilitate learning opportunities in large and small ways.

- Diverse learning abilities are provided for (at-risk, disabilities, expert learners)

- The reliability and functionality of delivery mechanisms are continuously evaluated

- Learner-centered courseware is provided

- Feedback from learners is taken seriously and used for continuous improvement

- Courses that students want are available when they want them

- Connectivity to multiple opportunities for learning and service is provided 
16. How can specialized online student services and resources make access easier?

Pace University supports students with online support services, including math tutoring, and measures the effectiveness of these services.

The University of Phoenix provides one-click access to student services and resources directly from online courses.

$\underline{\text { Saint Leo University provides online access to community-building activities and opportunities. }}$

Community College of Baltimore County, Essex offers a "walk through the web" course in several formats to introduce students, faculty and staff to all of the services that are provided on CCBC-Essex's web site.

Connecticut Distance Learning Consortium provides eTutoring.org, a collaborative program and platform that shares tutoring expertise among member institutions, thus giving students access to more support.

Kentucky Virtual University (KYVU) enables students from participating institutions to register for KYVU courses using common application and registration forms.

The Pennsylvania State University responds rapidly to users, emphasizes service, and projects a distinctive identity through its website that provides a smooth connection to information, programs, and services.

For a highly mobile learner population, GoArmyEd (formerly eArmyU) provides U.S. Army Soldiers unprecedented access to all the resources needed to pursue higher education while simultaneously serving in demanding work environments.

So students can get information any time, Maryland AskUsNow is a 24/7 live online interactive library service that uses the expertise of librarians to provide Maryland residents with answers to questions, research guidance, and help navigating the Internet. The University of Maryland University College 's electronic document delivery service allows UMUC students and faculty to access journal articles and book chapters. At Davidson College, open access to scientific journals online means more equitable access, and using primary published research results can enhance student learning by developing critical and other higher-order thinking skills.

To ease and speed admission processes, Saint Leo University reports transfer credit rapidly from its data base of thousands of sources of equivalencies and provides degree completion program outlines quickly. For students who want customized learning help, SMARTHINKING provides anywhere, anytime tutoring in real time one-on-one online tutoring services to students. Pace University provides a tip for enhancing access - use mid-week start/end frames for assignments; at Pace, working adults prefer midweek rather than weekend due dates.

At New Jersey Institute of Technology, Professor Murray Turoff designed a one room schoolhouse so that students can choose to attend blended or face to face sections of the course. 


\section{How can schools help students access support and adapt to academic culture?}

When students decide to enroll, Boise State (BSU) helps them visualize the enrollment procedure via an online flowchart; BSU's "boot camp" is an asynchronous online training program that prepares students for succeeding online. Northern Virginia Community College provides many ways for prospective students to find out about courses; before enrolling; its continuous enrollment and expandable course sections help meet growing learner demand for more access. The State University of New York Learning Network (SLN) provides learners and faculty access to online learning communities as critically important learning resources.

Access also means that students are aware of choices and resources, thus Fairleigh Dickinson seeks to meet its objective to create skilled lifelong global learners by requiring all of its undergraduates to take online courses. Pace University's university/industry partnership with CAEL, the Council for Adult and Experiential Learning and the telecommunications industry provides access for telecommunications employees and their employers. Maryland Digital Library (MDL) provides online electronic library resources to Maryland higher education institutions. Two pilot projects at the University of Helsinki demonstrate the potential of mobile learning to increase access to learning opportunities and resources. Once students are enrolled, access includes helping students make education more affordable, thus Embry-Riddle Aeronautical University makes buying and selling used textbooks online easy.

\section{How can schools provide access to special populations?}

The University of Washington's DO-IT (Disabilities, Opportunities, Internetworking, and Technology) Center makes distance courses accessible to students with disabilities, provides resources about accessibility online, and promotes the accessible design of online courses nationwide. The Western Cooperative for Educational Telecommunications provides students, researchers and administrators with guidance for time- and location-independent support and information services, including academic advising, career planning, financial aid, library services, orientation, personal counseling, tutoring, disability services, call centers, and for re-engineering student services. An exemplar of such services is Rio Salado, which uses a systems approach to online learning: its integration of the activities of course development and support, student services, faculty services, information services, admissions and records and marketing departments makes Rio able to offer students hundreds of unique courses, with $90 \%$ of the courses available for students to enroll in every two weeks (twenty-six start times per year), with the remainder of the courses usually available for enrollment six to eight times per year. Rio never cancels a class, even if only one student enrolls. James Madison University provides summer online courses so that students can meet their graduation requirements when courses are inaccessible during the Fall and Spring terms on campus.

Access to learning for specialized populations of learners occurs in various discipline-based courses with practices that might be adapted or use across disciplines, like these in:

\section{Business: \\ $\underline{\text { FCIB, }}$ an association of executives in finance, credit, and international business, and Michigan State University Global (MSU Global) formed an innovative partnership that applies an instructor-led, cohort- based model for corporate online learning and leads to certificates in international credit and risk management. University of Central Florida provides a 3-D Interactive Accounting Model that motivates students to understand and manipulate inputs and outputs. At Ohio State University, a Statistical Buffet gives students choices for their own mix of activities for learning the same set of course objectives.}


Using automated course administration and individualized web content optimizes each student's experience and improves success rates. At Morrisville State College an IT internship provides field-work in a selected business, industry, government or educational setting. This real-world work experience gives students "increased confidence in their own technical abilities. To date, more than 90 percent of interns have received offers of full-time employment by their internship sponsor."

\section{Education and Computer Science:}

At Harvard University, modeling experiential learning and exemplary standards helps learners use various pedagogies, media and technology to improve learning. Rice University connects teachers in training with virtual guests who are expert teachers through asynchronous discussions; virtual guests can host asynchronous interactive discussions and students can interact with them expressing individual concerns without time and place constraints.

At the University of Massachusetts Lowell, a course in theory and research in curriculum keeps students current with virtual textbooks, web hot spots, and weekly newsflashes. The University of Virginia provides virtual electronics laboratories using visual representations of microelectronics devices to help students internalize concepts.

To foster students' critical thinking and interpersonal skills, and enable students to make connections between service and their academic work, Bemidji State University's Distributed Learning in Teacher Education (DLiTE) program uses e-service for experiential service learning opportunities in online courses. At the University of Illinois, Urbana-Champaign, the Library and Information Science program creates a significant difference in the way students participate in a rapidly changing profession, including helping learners is to create a community of practice in the new online environment.

San Francisco State University conducts a learn-by-doing course in Training Needs Assessment in which teams of students perform needs assessments for real clients in corporate, non-profit, higher education, and $\mathrm{K}-12$ education settings.

\section{Engineering:}

The University of Toledo's (UT) collaborative partnering approach enables UT to offer engineering technology online degree programs statewide.

Stevens Institute of Technology, in partnership with several scholarly global organizations, provides graduate engineering certificate programs online

\section{Environment:}

The University of Wisconsin-Stevens Point (UWSP) Extension offers environmental studies online and in hybrid formats.

NOAA's interactive course: Collaborative Processes, is a self-paced series of interactive modules explores roles and processes, stakeholders, meeting and conflict management, and assessment of task/process behaviors can help identify individual and collective styles.

\section{Health:}

Creighton University provides a Doctor of Pharmacy degree, expanding access to underserved 
populations in rural areas that are not within driving distance of a place-bound pharmacy school. Rochester Institute of Technology, in conjunction with the Monroe County (NY) Health Alert Network (HAN) and the New York State Association of County Health Officials (NYASCHO), funded by a grant from the Centers for Disease Control (CDC), offers instructor-led online learning for adult voluntary learners who need job-related training.

\section{Humanities:}

Integrated Medical Curriculum (IMC) provides The Doctor's Dilemma, an interactive medical ethics roleplaying program that uses text- and photo-based material to explore "complex or controversial issues found in contemporary medical practice" through role-playing.

Minneapolis College of Art and Design's Distance Learning Initiative re-creates the studio-based model online for art and design education.

Goucher College's MA in historic preservation is a hybrid program that requires one in-person introductory meeting.

Boston Architectural Center offers online professional design education, a field which relies on expressive representation, subjective interpretation, and critique in a wide range of graphic, verbal and quantitative media.

\section{Science:}

Western Washington University's integrated laboratory network (ILN) provides better access to scientific instrumentation and expertise anytime, and from anywhere by allowing students and researchers to operate instruments located at different campus locations via the internet. The ILN also enables direct exchange of information, data, and classroom material, modeling the virtual laboratory of the future, enabling learners and teachers to apply the philosophy that science is a dynamic, iterative, ongoing, and collaborative process. Northern Virginia Community College provides chemistry laboratories for science majors using home laboratories, computer exercises, field trips, and college laboratories to improve access and learning experience. The University of Colorado at Denver (UCD) offers lab-based science courses in online and hybrid formats for anytime anywhere chemistry experiences.

\section{How can schools use technology to improve access?}

Training users and employing technologies that simplify operations eases access for various constituents in organizations. The University of Illinois - Springfield facilitates technical support with screen capture software, GifgIfgiF, that animates software demonstrations; and it uses Impatica to reduce the need for plug-ins, converting PowerPoint lectures into streaming Java presentations. Duquesne University enables learning-on-the-go for access to course and study materials so that busy adult students can listen to audio recordings any time via MP3. Washington State University 's Distance Degree Programs uses streaming technologies to publish course descriptions, faculty bios and student testimonials in close-captioned streaming audio with revolving photos, allowing students an opportunity to quickly and easily see and hear the fine details of WSU-DDP online courses. At Atlantic Cape Community College, faculty-staffstudent partnerships produce reusable and shareable learning objects. Distance learning faculty specialists bridge the gap between faculty and administration through the Distance Learning Faculty Specialist (DLFS) model, developed by Eastern Oregon University to help involve faculty in distance education. The University of South Queensland (USQ) is building strategically planned, systematically integrated, institutionally comprehensive implementation of information and communication technologies including 
automated responses, intelligent object databases, and other information and communication technologies, including automated response systems and intelligent object databases to automate certain aspects of interaction with students, increasing access to higher education on a global scale. At San Francisco State University, some courses use the "HyFlex" course and design process so that students may choose to attend face-to-face synchronous class sessions or complete course learning activities online without attending class in person.

\section{FACULTY SATISFACTION}

Faculty satisfaction with online teaching reflects institutional commitment to building and sustaining environments that are personally rewarding and professionally beneficial. The practices listed here include resources and strategies for ensuring faculty success.

- Faculty satisfaction metrics show improvement over time

- Faculty contribute to, and benefit from online teaching

- Faculty are rewarded for teaching online and for conducting research about improving teaching online

- $\quad$ Faculty experiences, practices and knowledge about online learning is part of the institutional knowledge sharing structure

- There is a parity in workload between classroom and online teaching

- Significant technical support and training are provided by the institution

\section{How can schools foster greater community among faculty?}

One of the great benefits for faculty who teach online is the opportunity to connect with new communities. Within these communities, quality is a frequent topic for discussion, activities and resource sharing. Maryland Faculty Online provides affordable faculty technology training via the Faculty Online Technology Training Consortium (FOTTC); its Project Synergy is a collaborative effort to train Maryland faculty in the 23 higher education institutions. FOTTC gathers, reviews, enhances, and disseminates interactive, technology-based, Web-accessible learning objects for use in key discipline areas. The project has enabled faculty to develop a repository of over 100 Web-accessible learning objects in six key discipline areas; the learning objects are enhanced with assignments, assessments, and instructions for using these learning objects effectively. The project has also developed models for enhancing learning objects in the disciplines. The project helps to establish the Maryland Faculty Online web site as the statewide web-based training center for the ongoing professional development of faculty. The University of Calgary's best practices in e-learning online showcase enables practitioners in e-learning to meet, share and showcase their best practices with each other. University of Illinois at Chicago (UIC) and Great Cities Institute integrate adjunct faculty into the community of practitioners through activities and incentives. The University of Massachusetts Lowell promotes faculty collaboration through an online faculty book club; the book club enables faculty to discuss issues and share effective practices. Florida Community College at Jacksonville Distance Learning uses a virtual mentoring program to support online adjunct faculty with instructional and technical support and to liaise between faculty and Virtual College staff. At the University of Massachusetts Lowell, veteran online faculty mentors become cyber-celebrities and guest speakers who interact and share their experiences with faculty new to online teaching and course development. George Mason University created a faculty fellows program to increase faculty skills and interest in online education and to provide social and technical support. Florida State University recognizes faculty as WebStars and publishes their effective teaching tips on special web pages for sharing knowledge about using technology to improve quality of instruction. California State University, 
Chico provides an online rubric for online instruction to demonstrate and encourage exemplary faculty work in online education.

Members of online communities can stay abreast of the rapidly changing environment and apply information to the development of their online offerings by subscribing to University of Illinois Springfield daily blogs on new and developing initiatives, methodologies, and technologies in ALN.

\section{How can schools prepare faculty to teach online more effectively?}

Faculty preparation for teaching online measurably improves learning effectiveness and satisfaction. Thus, because learning effectiveness also focuses on faculty, The Pennsylvania State University provides a self-paced faculty development program that helps faculty understand distance education students; recognize how distance education differs from traditional resident instruction; determine course goals, learning model, and content; determine course assignments, interactions and assessments; choose delivery technology; and understand legal issues in course design. The program includes guidelines for clear communication and netiquette. Another useful self-paced teaching aid is the Learning to Teach with Technology Studio (LTTS) at the Indiana University (IU) School of Education. This program offers K-12 teachers forty five online courses that include email facilitation and a standard course structure. The structure of courses is described in an online IU tour:

- $\quad$ Problem: Introducing the problem

- Process: How to go about solving the problem

- Solution: Completing the course project

- $\quad$ Assessment: How your work will be assessed

- $\quad$ Resources: What resources are available to help you

To enable faculty to design courses and control the quality of content, schools and organizations provide training and resources. At Berkeley College, faculty training and support are available totally online via

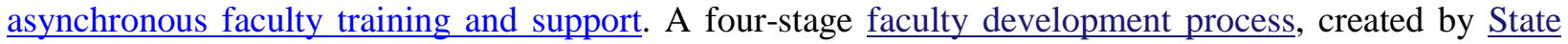
University of New York Learning Network, leads to high faculty satisfaction with teaching online. The Monroe Model, created by Monroe Community College, is a site-based and online support framework that addresses any issues or questions faculty might face. CoreOnline at Boise State University is a graduated faculty development model, in which teams of faculty learn online instruction skills and practice them as they collaborate on the development of a targeted general education core course. At University of Nebraska Lincoln's Extended Education and Outreach, a five-week online summer faculty development program of training for online teaching takes both novice and experienced online instructors through the steps of course development and management, online teaching, and online assessment. The Berkeley College Online Faculty Resource Center is a media-rich interactive site that provides faculty with comprehensive resources. Catalyst is the University of Washington 's online faculty guide to distance teaching ; Catalyst uses multiple feedback mechanisms (e.g., focus groups, online evaluations, surveys, usability studies, e-mail and face-to-face comments) to assess its effectiveness and overall impact. The learning to teach online program (LeTTOL) program, created by South Yorkshire Further Education Consortium, helps participants gain the skills they need to develop and deliver online courses. At Dallas Baptist University, an online teaching tips website is open to public use and commentary. Faculty teaching online find that knowing behavior patterns improves teaching and learning, thus researchers at the University of Central Florida design learning activities and interaction to correspond to learners' energy levels, need for approval, and styles of dependence and independence. For teachers in training, a professor at the University of Central Florida shows students how to create digital stories that help teachers learn to use multimedia and their students to learn vocabulary. 
North Carolina State University Distance Education and Learning Technology Applications (DELTA) RFP Program, created by North Carolina State University, funds faculty in the planning, design, and development of distance education programs.

\section{How can schools encourage and support research opportunities for faculty?}

In the relatively young field of online education, faculty and others enjoy opportunities for research and publication. The Indiana Partnership for Statewide Education has assembled guiding principles for faculty in distance learning online to help faculty members teach courses online. The Greater Detroit Area Partnership for Training improves faulty satisfaction with its analysis of faculty experience and standards of excellence that addresses concerns identified by faculty feedback.

\section{How can schools recognize and reward faculty who teach online?}

Studies like the above can lead to initiatives that improve faculty satisfaction by rewarding faculty for their achievements in development, research and teaching online. In its ongoing study and enhancement of faculty satisfaction, The Pennsylvania State University World Campus implements three principles to study and enhance faculty satisfaction: proactively and continuously managing expectations, distinguishing between "real" and "perceived" problems, and identifying and targeting the locus of control and change; its multidimensional recognizes and rewards faculty for online activities. The Northeastern University Center for Innovative Course Design rewards faculty through student-nominated faculty awards for effective and innovative technology use - faculty receive recognition for effective or innovative use of technology to support good teaching and learning; students feel empowered by nominating examples of effective practice. Auburn University has fundamentally transformed its tenure and promotion process giving faculty more freedom of choice for spending time and resources. And Indiana University Purdue University Indianapolis includes technology scholarship in its faculty reward structure for the use of technology for teaching and learning.

\section{How can technology help organize and enhance faculty activities?}

Technology enables rapid distribution, integration, and feedback of information that can lighten faculty workload. Uni Open Platform for instructor support and workload management, created by FernUniversitat Hagen, automates administrative processes, allowing faculty members to spend more time supporting and advising students.

A professor at the University of Maine at Fort Kent continuously improves his syllabus, incorporating and publishing results by annotating the syllabus during course delivery; using feedback for reflecting, evaluating, and planning ahead; and by documenting and sharing the improvements made to his course. At Athabasca University, faculty members can update their materials themselves via their browsers with the use of blogging software with an estimated $90 \%$ reduction in the time usually taken to update online course materials from two weeks per semester to one day; to keep the community current with tools, Athabasca graduate students compare the growing array of LMS software at http://cde.athabascau .ca/softeval/. Berkeley College uses Intranets Conferencing, a commercial service that enables faculty to confer online and develop or modify an online course, incorporate media, and have their questions, problems, and concerns attended to quickly and easily anywhere and any time. At the University of Houston (C.T. Bauer College of Business), faculty share ethics learning objects to save faculty development time. 
The Learning Online Network-Computer-Assisted Personalized Approach (LON-CAPA), developed at Michigan State University, is open source software that enables instructors to create computer-assisted personalized assignments, quizzes, and examinations. The Multimedia Educational Resource for Learning and Online Teaching (MERLOT) peer reviews online teaching-learning materials and publishes materials online, making them freely available to faculty everywhere.

At Berkshire Community College, a blog supports faculty development; the blog includes summaries of events, links to articles of interest, video clips of workshops, calls for proposals, and professional development opportunities. Kansas State University shares its ELATEwiki with faculty and students and also with the public. The wiki is useful in many ways:

First, it allows expert teachers to share their knowledge in a fast and effective way. It allows these experts to correct and improve on ideas contributed by others. Second, novice teachers can use ELATEwiki to learn new techniques and explore ideas for improving their teaching. They can also contribute cutting-edge ideas and ensure new knowledge is made available to more established teachers. Third, ELATEwiki supports classroom access to material. Not only is the material on ELATEwiki available as a student resource, it can be used as a site for developing and posting student projects that are visible to the entire world. This sense of moving a project beyond the classroom and making it a valuable artifact tends to motivate performance and encourage collaboration between student team members, peers, experts outside the classroom, and teachers. And finally, ELATEwiki's access feature ensures that meaningful and effective access will follow the student as they move from academic to professional life.

\section{CONCLUSION}

The practices in this synthesis may be refined for local contexts and adapted across a wide range of institutions. Thanks to the generosity of effective practices contributors, the questions in this synthesis identify some ways asynchronous learning networks are transforming higher education. Yet, the questions are by no means comprehensive, and the practices suggest a multitude of innovations still to be developed and shared. Readers are welcome to add questions and comments, to build on these ideas, and to contribute more practices to Sloan-C Effective Practices so that the goal of quality, breadth and scale in anytime, anywhere education becomes a reality for more learners than ever before possible.

\section{REFERENCES}

1. The Pillar Reference Guide, http://www.sloanconsortium.org/sites/default/files/pages/SloanC\%20Pillar\%20Reference\%20Manual.pdf.

2."Beyond the Administrative Core: Creating Web-Based Student Services for Online Learners," Western Cooperative for Educational Telecommunications (WCET), 2002. Online: http://www.wcet.info/projects/laap/.

3. Swan, K. Relationships Between Interactions and Learning In Online Environments (PDF 486KB). http://www.sloanconsortium.org/publications/books/pdf/interactions.pdf.

4. Bishop, T. Research Highlights: Cost Effectiveness of Online Education. (PDF 484KB). http://www.sloanconsortium.org/publications/books/pdf/ce summary.pdf.

5. Oakley, B. \& J. Moloney. Scaling Online Education: Increasing Access to Higher Education. Journal of Asynchronous Learning Networks 10(3): July 2006.

\section{APPENDIX A: AWARD WINNING EFFECTIVE PRACTICES}


A Systems Approach to Online Learning

Multidimensional Model for Review of Scholarly Activity

Online Support Services -- Focus on Student Satisfaction

Anytime Anywhere Chemistry Experience

Cost-Effective Distributed Learning with Electronics Labs

Asynchronous Audio Feedback to Enhance Teaching Presence and Students' Sense of Community

Combining Effective Individualized and Group Instruction

Content Area Vocabulary Digital Stories

Discipline-Specific Online Writing Lab with 24/7 Access and Asynchronous Peer Tutoring

Effective Feedback to the Instructor from Online Homework

ELATEwiki: E-Learning and Teaching Exchange Wiki to Support Faculty Development

Engaging Students Through Electronic Peer Review

Faculty Self-Study Research Project

Integrated Laboratory Network: Better Access to Scientific Instrumentation

Providing anytime, anywhere online access to higher education for a highly mobile learner population

Repurposeable Learning Objects: the TALON Learning Object System

Supporting Online Adjunct Faculty: A Virtual Mentoring Program

The Real-Time Case Method: Access to Real-Time, Real-World Cases

The Statistical Buffet

Using Cohorts to Build an Online Learning Community

Using Quality Matters to Guide Online Course Development

Using the "HyFlex" Course and Design Process

Using the Community of Inquiry Framework Survey for Multi-Level Institutional Evaluation and

Continuous Quality Improvement

WISE, A Collaborative Distance Education Model for Library and Information Science

Wizards: Student Tutors Help Peers Learn

Mixed Delivery Model Proves Cost-Effective

\section{APPENDIX B: RUBRIC FOR EVALUATING EFFECTIVE PRACTICES}

\footnotetext{
1. Innovation: The practice is inventive or original in realizing the potential of online learning and related information/communication technologies.

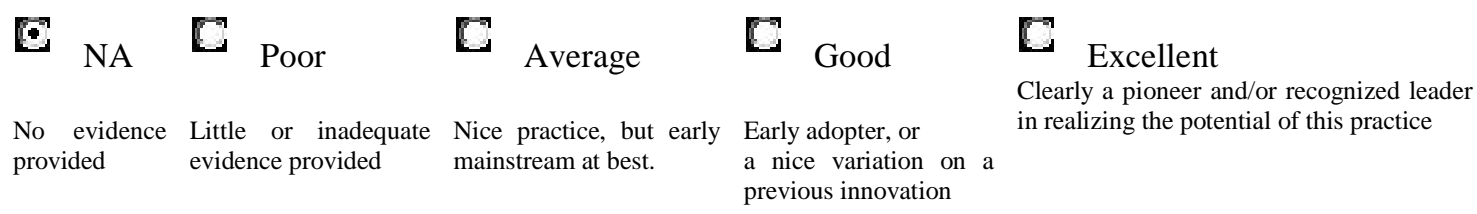

2. Replicability: The practice can be implemented or its resources shared in a variety of learning environments. 


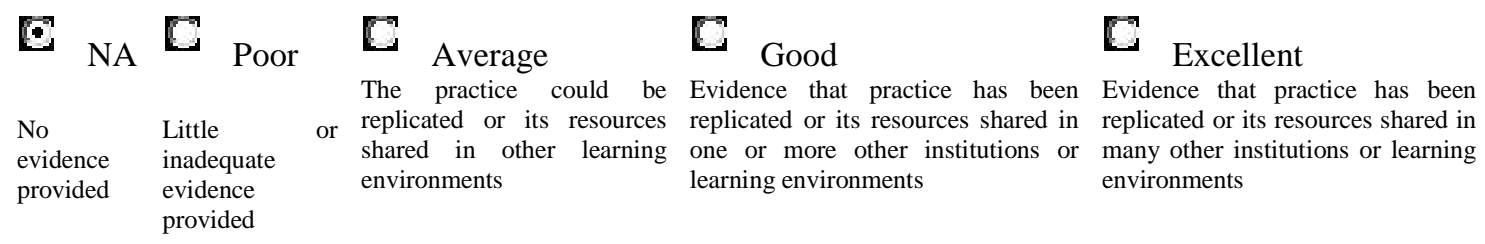

3. Potential impact: Wide adoption of the practice will improve learning, affordability, access and/or satisfaction among providers and/or users.

$\begin{array}{llll}\text { NA } & \text { Poor }\end{array}$

4. Supporting documentation: The practice supports claims of effectiveness with research and/or other empirical data.

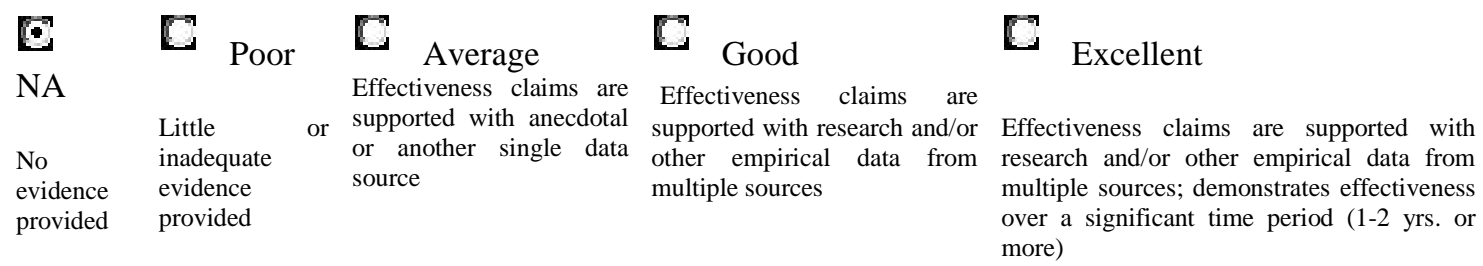

5. Scope: The practice demonstrates relationships among learning, affordability, access, and faculty and student satisfaction.

\begin{tabular}{|c|c|c|c|c|}
\hline$\Leftrightarrow$ & Poor & Average & Good & Excellent \\
\hline $\begin{array}{l}\text { No evidence } \\
\text { provided }\end{array}$ & $\begin{array}{l}\text { Little or } \\
\text { inadequate } \\
\text { evidence provided }\end{array}$ & $\begin{array}{l}\text { States how the practice } \\
\text { relates to one or more } \\
\text { other pillars }\end{array}$ & $\begin{array}{l}\text { Demonstrates a strong } \\
\text { relationship with one } \\
\text { other pillar }\end{array}$ & $\begin{array}{l}\text { Demonstrates exceptionally strong relationship } \\
\text { with another pillar, or demonstrates strong } \\
\text { interrelationship with several other pillars }\end{array}$ \\
\hline
\end{tabular}

\section{Additional Comments:}

